\title{
Analysis on the Efficiency Function of Procedural Law
}

\author{
Xu Hui ${ }^{1}$, Wan Yinghua ${ }^{1}$, Yue Ruijie ${ }^{1}$ \\ ${ }^{1}$ Xingtai University, Xingtai, 054001, China
}

Keywords: Procedural law. Efficiency function. Efficiency. Restriction factor. Jurisdiction

\begin{abstract}
The two basic value embodiments to guarantee the procedural law are reflected in its fairness and efficiency. The efficiency function of procedural law can improve the jurisdiction efficiency effectively, which is the both the character of procedural law itself, and the basic rule to implement the effect function of procedural law. Compared with the foreign countries, the procedural law in China has not been so perfect, and there is no perfect concept of procedure procedural justice and the overall structure of procedural law is not so scientific and reasonable, restricting the full use of efficiency function of the procedural law; only by continuously perfecting the procedural law can the efficiency function of the procedural law be fully played and applied in the law reasonably. Aimed at the efficiency function of the procedural law, the author makes a brief analysis and explains his own opinions for reference by the peers.
\end{abstract}

\section{Introduction}

For a long time, the judicial personnel in China have always the pursued the judicial fairness blindly and take judicial fairness as the first objective of procedural law, but ignore the importance of judicial efficiency. Such thought deviates from the basic value objective of jurisdiction, and does not conform to the requirements of modern society for the jurisdiction. Xiao Yang, the 10th president of the supreme court of China once pointed out that "at present, the society is changing increasingly, therefore it is not allowed that the procedural activities waste time to some extent; currently, the criminal event increased, and the number of crime sharply increases with a serious situation, so the judicial authorities cannot main stable any longer; with the enhancing of people's consciousness of right maintenance, there is a stronger and stronger maintenance of interest, therefore, the work efficiency in judicial activity must be improved. From the aspect of western countries, from the 1960s, under the trend of rapid economic development, the western developed countries have also gradually improved the attention to the efficiency value created by the judicial activities, and paid more attention to the economic problems existing in the procedures, the efficiency power has become a difficulty faced by the judicial authorities. It has become a public difficulty that must be solved for various countries to amend the procedural law on how to implement the existing judicial efficiency and guarantee the fairness of jurisdiction and realize the two major objectives of procedural law.

To realize the efficiency objective of procedural law is a very complex process, it is required to fully consider the conditions of whole and individual, own factors and external factors, and this is only approach to realize the efficiency function of procedural law. To realize the judicial efficiency, it is required to implement the efficiency function of procedural law earnestly and fully make full use of the judicial efficiency while playing the efficacy function of procedural law.

\section{Procedural efficiency function can improve the judicial efficiency}

The efficiency function of procedural law is mainly to achieve the purpose of improving jurisdiction by implementing the procedural law, the procedural law efficiency function mentioned is not the efficiency model simply, and not to take the improving of judicial efficiency as the main value objective of procedural law, nor to ignore the fairness of procedural law, but to realize the two basic objective values of fairness and efficiency and make the two balanced. Through example, we can know that if the original second-instance-being-the-final-instance process is adjusted as the first-instance-being-the-final-instance process, the superficial change cannot meet the requirements 
of efficiency function, and it is also unable to meet the requirements of legislation. While the final objective of each trial is achieved with the minimum consumption, and popularly, to obtain the maximum benefit at the minimum cost. For example, sometimes for some parties concerned, the first-instance-being-the-final-instance process is more appropriate for the winning party, and it is no need to sped a lot of manpower and materials in the second trial in case of unnecessary trouble. In the opinion of most people, the regulation to the judicial proceedings seriously prevents the work efficiency of judges, and for efficiency, it belongs to a negative role, however, such requirement of the judicial law is aimed to restrict the behaviors of judges, and promote their work more regulated, then when dealing with the trials, the judges will use more resources to solve more problems, and the time and energy consumption promotes the improving of efficiency. A scholar from Britain once said that "the procedural regulations will prevent and limit the activity range of the government and doing according to the regulations will cost a lot of manpower and materials. However, if detouring the conflict with the government, the manpower and materials will be fully used, and the main reason is that the adherence to the fairness of procedures can eliminate additional trouble. In addition, the procedural principle can promote efficiency effectively." This sentence is aimed at administrative procedural rules, but the aim reflected is also applicable to the judicial procedures. The judicial proceedings can effectively promote the parties concerned to fully affirm the jurisdiction, reduce the possibility of mutual conflict between the parties concerned and the judicial authorities and eliminate the unnecessary troubles further realize the judicial fairness by realizing the fairness of procedural law and maximize the interest of the parties concerned, and this fully represents the efficiency power of the procedural law.

The efficiency function of procedural law is reflected in its obvious improving of judicial efficiency

The existing judicial proceedings are the joint product of accumulative judicial course and continuous improving and perfection by the following judicial personnel. Different procedural methods have different judicial proceedings, and the same form of action will also have different judicial proceedings according to different maximum benefits of the parties concerned. For example, the general civil cases with clear facts, definite responsibility relation and in which both parties reach consensus are appropriate to be treated with the simple procedures. The general civil cases are all appropriate to be treated with the simple procedures, and other civil cases are appropriate to be treated with ordinary procedures. In this way, it is possible to avoid inputting excessive time and money by the judicial authorities and the parties concerned to waste manpower and materials and further influence the lawsuit efficiency. Distinguishing the simple procedures and the ordinary procedures can effectively save the cost and effectively improve the lawsuit efficiency.

\section{The efficiency function of procedural law is reflected in its better regulation and higher authorization}

The judicial proceedings are the conclusion made by the human beings after rationally thinking over and analyzing the events, and are somewhat authoritative. Meanwhile, the procedural law itself has the objective of fair value with reasonable procedures. Therefore, as long as the judicial power is exercised through the justified procedures, the jurisdiction is fair, on the contrary, it is unfair. Only by performing the certainty, legality, regulation and authoritativeness of the procedural law can the authoritativeness of jurisdiction be realized to further improve the lawsuit efficiency.

The efficiency function of procedural law is reflected in the significant improving of judicial efficiency

Procedures fully reflect the efficiency characteristics of the jurisdiction itself. To realize the efficiency objective of jurisdiction, the justified judicial proceedings must be followed. If a case is delayed and cannot be determined as soon as possible, the legal rights and interests of the parties concerned will be damaged to some extent and the fairness of the case will be influenced. Settling a lawsuit as soon as possible the legal right and interest of civilians in a country under the rule of law, and also one of the bases to judge the justice of jurisdiction, which can also effectively improve the lawsuit efficiency. 


\section{Effective analysis on factors influencing the efficiency function of procedural law}

All lawsuit activities have certain timeliness and will be limited by time, and a the settlement of a case cannot be delayed repeatedly. Judging a lawsuit case is the important premise for a country under the rule of law to implement the legal procedures. The timeliness of law fully reflects the efficiency power of procedural law.

The timelines of lawsuit activities is reflected in the limitation to the time of lawsuit activities when the people's court, parties concerned and relevant personnel participating in the proceedings and it is specified to accept and settle the lawsuit case within the specified time. For example, in the civil cases, when the court prosecutes the parties concerned orally or in the form of indictment, if the prosecution condition is met, the case will be treated within one work week generally, and if the condition is not met, the case will not be accepted. Within 5 workdays after filing, the copy of the incitement needs to be issued to the defendant, and the defendant will have 15 workdays to prepare for the reply, and meanwhile, the copy of the answer will be issued to the plaintiff within 5 workdays after reply. Finally, the court will settle the case. The case settlement time is generally limited within 6 months.

The timeliness of the lawsuit activities effectively maintains the lawsuit efficiency and maintains the legal rights and interests of the parties concerned. Combining the two together, China and other countries under the rule of law have express specifications. However, there exist some loopholes in the process of implementing the timeliness, and the efficiency function of procedural law is limited, which is mainly reflected in the non-scientific, unreasonable and imperfect procedural law and unclear specified timeliness for the procedural law. The perfection of legislation must conform to four basic rules: 1 . guarantee the timeliness of unveiling, when unveiling the new laws and regulations, it is required to amend the original ones; 2 . guarantee the completeness of contents; 3. guarantee the consistency of direction and ensure that various laws and regulations are harmonious and unified without mutual conflict; 4 . guarantee the final purpose of law. According to the analysis by reference to the above four points, relevant provisions in the procedural law of China are imperfect and needs to be further improved. The judgment manner is complex, and there is a lack of application for the efficiency function of procedural law, which are both the important factors for imperfect procedural law of China, and finally restrict the playing of efficiency function of the procedural law.

\section{Effective condition to realize the efficiency function of procedural law}

Only by fully making use of the efficiency function of procedural law can the value of procedural law be reflected. To reflect the value of procedural law, it is required to guarantee the scientificness and reasonableness of the procedural law itself.

To fully make use of the efficiency function of the procedural law, it is required to adhere to the scientificness and reasonableness of the procedural law itself. The scientificness and reasonableness of procedural law are the important factors to influence the efficiency power of the procedural law, which should have the characteristics of clear target, strong operability of procedures and scientific and reasonable systems etc. The efficiency function of the procedural law is mainly reflected in the following: timeliness, institutional property and procedural property.

There are many items unscientific and unreasonable in the procedural law of China, aimed at the defection of timeliness of procedural law analyzed above, currently, it is urgent to established an ordered timeliness system, and meanwhile, make clear the legal consequence of failure to follow. The failure of judicial authority to operate according to the justified procedures should be regarded as illegal behaviors, and relevant personnel must undertake the legal liabilities.

The institutional property is mainly reflected in the one-evidence system. First, expressly specify the timeliness of listing evidences; second, expressly specify that evidence exchange must be required before trial to prevent the influence on the whole trial process due to uncertain factors in the proceeding process to reduce the lawsuit efficiency; third, expressly specify that when both parties state the evidences, keep the court silent, avoid quarrel due to different opinions on the evidences to 
reduce the lawsuit efficiency; fourth, expressly specify that forging evidence should be punished and forging evidence should be deemed as contempt of court and prevention of judicial fairness and the punishment system for evidence forging must be perfected, so as to make full use of the efficiency function of the procedural law.

The procedural property is reflected in the simple procedure. It is required to gradually break through the limitation of simple procedures and expand its applicable scope, so as to save the judicial resources and it is required to establish the simple procedures for procedural law. Meanwhile, for the small amount of debt dispute case, it is possible to adopt the trial methods of installment payment and small amount for more periods, so as to settle the debt dispute effectively. At the same time, the legal procedure is simplified and the lawsuit efficiency is further improved.

To fully make use of the efficiency function of the procedural law, it is required to build a correct judicial concept. At present, China is lack of the consciousness of procedure justice concept and the judicial procedures formed exist in name only. Only by building the correct procedure justice concept and building the concept of having a judicial judgment to the case timely and strictly complying with the express provisions of procedural law can we effectively solve the phenomena of delayed trial. The judicial proceedings can maintain the legal rights and interests of the parties concerned, and the lawsuit activity itself will be limited by the manpower, material and fiancé, while the judicial judgment can fully reflect the lawsuit efficiency. Therefore, the effective approaches to improve the lawsuit efficiency can only be to effectively reform the jurisdiction effectively, abolish the unnecessary approval links and meanwhile improve the judges' quality.

To fully make full use of the efficiency function of the proceedings, it is also required to get the full affirmation and recognition of the parties concerned and the mass to the procedural law. Popularizing legal knowledge to the public and carrying out long-term legal education are beneficial for the mass to identify the procedural law. The higher the identity to law is, the more obvious the effect for legal implementation will be.

\section{Conclusion}

In a word, it is required to make full use of the efficiency function of the procedural law, combine it with the fair value objective of the procedural law, realize the overall value objective of procedural law, further improve the jurisdiction efficiency and realize the jurisdiction fairness. The only effective approach to realize the efficiency function of the procedural law is to break through the factors restricting the efficiency function of procedural law. Therefore, it is required to attach importance to the jurisdiction efficiency character of procedural law itself, the regulation and authoritativeness of judicial proceedings and the jurisdiction efficiency characteristics of jurisdiction itself, fully reflect the scientificness and reasonableness of procedural law and timeliness, institutional property and procedural property of the efficiency function, build up the correct justified jurisdiction concept and improve the lawsuit efficiency through justified procedures and meanwhile, popularize the public's legal awareness and carry out long-term legal education to them, so that they can identity the procedure law. It is also required to perfect the procedural law system, organically combine the internal condition with the external condition of procedural law, and only in this way can the efficiency function of the procedural law be fully played.

\section{References}

[1] Chen Qianxin, Analysis on Several Issues of Amendment to Criminal Procedural Law (Draft) [J], Journal of Shijiazhuang University, 2012 (02)

[2] Xiong Qiuhong, Overhaul to Criminal Procedural Law: Lingering between the Ideal and Reality [N], Chinese Social Sciences Weekly, 2012 (07) 
[3] Liao Wengen, Earnestly Learn and Carry out the Modified Criminal Procedural Law and Punish Crime and Maintain the People's Rights and Interests Better According to the Law [N], People's Daily, 2012-05-27 (001).

[4] Huang Ermei, Earnestly Carry out the Modified Criminal Procedural Law and Practically Guarantee the Fairness of Criminal Judicial Proceedings [N] People's Court Daily, 2o12-06-13 (005)

[5] Zhou Yongkang, Deeply Learn and Carry out the Modified Criminal Procedural Law, Better Punish Crime, Guarantee Human Right and Maintain the Social Order [N], Legal Daily, 2012-05-29 (001)

[6] Wang Shengjun, Earnestly Learn and Carry out the Modified Criminal Procedural Law and Continuously Open Up the New Situation of Trial Work [N], People’s Daily, 2012-03-28 (008).

[7] Xiong Yunhui, Earnestly Treat the Implementation of Criminal Procedural Law [N], Legal Daily, 2012-05-09 (010)

[8] Zhao Chunyan, Bian Jianlin: Guarantee of Civilian Rights and Interests through "6 Points" of Criminal Procedural Law [N], Democracy and Legal Times, 2012-04-16(003). 